\title{
Prescribing-Assessment Tools for Long-Term Care Pharmacy Practice: Reaching Consensus through a Modified RAND/UCLA Appropriateness Method
}

\author{
João R. Gonçalves ${ }^{1, *}$, Betsy L. Sleath ${ }^{2}$, Manuel J. Lopes ${ }^{3}(\mathbb{D})$ and Afonso M. Cavaco $^{1}(\mathbb{D}$ \\ 1 iMed.ULisboa, Social Pharmacy Department, Faculty of Pharmacy, University of Lisbon, \\ 1649-003 Lisboa, Portugal; acavaco@ff.ulisboa.pt \\ 2 Eshelman School of Pharmacy, University of North Carolina at Chapel Hill, Chapel Hill, NC 27599, USA; \\ betsy_sleath@unc.edu \\ 3 College of Nursing S. João de Deus, University of Évora, 7000-811 Évora, Portugal; mjl@uevora.pt \\ * Correspondence: jgoncalves11@office365.ulisboa.pt
}

check for updates

Citation: Gonçalves, J.R.; Sleath, B.L.; Lopes, M.J.; Cavaco, A.M. Prescribing-Assessment Tools for Long-Term Care Pharmacy Practice: Reaching Consensus through a Modified RAND/UCLA Appropriateness Method. Pharmacy 2021, 9, 194. https://doi.org/ $10.3390 /$ pharmacy 9040194

Academic Editor: Bjarke Abrahamsen

Received: 15 November 2021

Accepted: 2 December 2021

Published: 3 December 2021

Publisher's Note: MDPI stays neutral with regard to jurisdictional claims in published maps and institutional affiliations.

Copyright: (c) 2021 by the authors. Licensee MDPI, Basel, Switzerland. This article is an open access article distributed under the terms and conditions of the Creative Commons Attribution (CC BY) license (https:// creativecommons.org/licenses/by/ $4.0 /)$.

\begin{abstract}
Medicines are the most used health technology in Long-Term Care. The prevalence of potentially inappropriate medicines amongst Long-Term Care patients is high. Pharmacists, assisted by prescribing-assessment tools, can play an important role in optimizing medication use at this level of care. Through a modified RAND/UCLA Appropriateness Method, 13 long-term care and hospital pharmacists assessed as 'appropriate', 'uncertain', or 'inappropriate' a collection of commonly used prescribing-assessment tools as to its suitability in assisting pharmacy practice in institutional longterm care settings. A qualitative analysis of written or transcribed comments of participants was pursued to identify relevant characteristics of prescribing-assessment tools and potential hinders in their use. From 24 different tools, pharmacists classified 9 as 'appropriate' for pharmacy practice targeted to long-term care patients, while 3 were classified as 'inappropriate'. The tools feature most appreciated by study participants was the indication of alternatives to potentially inappropriate medication. Lack of time and/or pharmacists and limited access to clinical information seems to be the most relevant hinders for prescribing-assessment tools used in daily practice.
\end{abstract}

Keywords: long-term care; potentially inappropriate prescribing; pharmacist; pharmacy practice; consensus; RAND/UCLA; prescribing-assessment tools

\section{Introduction}

Long-Term Care (LTC) encompasses a range of healthcare, personal care, and other supportive services targeted to patients whose capacity for self-care is limited over an extended period [1,2]. In Portugal, the National Network for Long-Term Integrated Care represents the country's response to the growing demand for this level of care. Structurally, the National Network for Long-Term Integrated Care (NLTIC) comprehends Home and Community-Based Services (outpatient settings) and Skilled Nursing Homes (inpatient settings). Pharmacists' intervention in NLTIC outpatient settings is absent. National Network for Long-Term Integrated inpatient settings is divided into 'Convalescence units', 'Medium Term \& Rehabilitation units', and 'Long-Term \& Maintenance units' [3]. Although not explicitly targeted to care for aged people, LTC populations are often elderly patients. In 2020, $84 \%$ of NLTIC's patients were aged 65 or over, aligned with the worldwide demographic ageing trend [4]. As extensively reported, the ageing process is highly associated with multimorbidity and, consequently, with augmented use of medications [5-7]. Older populations are more susceptible to Adverse Drug Events (ADEs) given the age-related pharmacokinetics and pharmacodynamics changes, adding to elders' usual under-representation in clinical trials. All previous reasons might explain the high prevalence of Potentially Inappropriate Medication (PIM) in older patients [8,9]. A recent systematic review identified 
a prevalence of inappropriate medication use among the elderly ranging from $11.5 \%$ to $62.5 \%$ [10]. In LTC facilities, the prevalence of inappropriate medication is also high [11-13]. Consequently, the quality of prescribing in LTC populations is of utmost importance, being a complex and challenging process. Potentially Inappropriate Prescribing (PIP) has been associated with negative health outcomes and economic losses [14,15]. Potentially Inappropriate Prescribing concept encompasses the following practices: (i) misprescribing, i.e., the prescription of a medication that could potentially lead to a significant risk of ADEs, due to erroneous posology or route of administration or due to increased risk of drugdrug or drug-disease interaction; (ii) underprescribing or Potential Prescribing Omission (PPO), i.e., the omission of a medication that is clinically indicated for disease treatment or prevention; (iii) overprescribing, i.e., the prescription of medications for which no clear clinical indication exists $[16,17]$. Different methods have been developed and implemented focused on inappropriate prescribing prevention, such as education, medication reconciliation, and prescribing-assessment tools [18]. Over the last three decades, several criteria and screening tools have been developed to assist clinicians in identifying and preventing PIP. These tools can be explicit (i.e., criteria-based) or implicit (i.e., judgement-based) [19,20]. Amongst the healthcare professionals capable of using such instruments are pharmacists. Pharmacists' practice encompasses several medicine-related interventions, from medicines management to establishing, assessing, or monitoring treatment plans. Through a set of clinical and patient-oriented activities and collaboration with other healthcare professionals, pharmacists can reduce PIP also in LTC settings [21,22].

Long-Term Care conceptualization and delivery vary from country to country, hampering scientific reporting and standardized utilization of Potentially Inappropriate Prescribing (PIP) assessment tools [23,24]. In Portugal, no common or generally accepted guidelines regarding therapy optimization are known in LTC. The existing heterogeneity of medication prescribing practices, the wide range of supporting instruments available, and the LTC population heterogeneous health status turns challenging to identify the most suitable Prescribing-Assessment Tools (PATs). This study aimed to identify the most suitable Prescribing-Assessment Tools useful for LTC pharmacy practice. An additional goal was to map key characteristics of Prescribing-Assessment Tools from the pharmacist-user perspective and potential hinders for their use.

\section{Materials and Methods}

This study followed a consensus-building methodology to select the most appropriate tools for pharmacy practice in LTC settings, adjusted to patients' characteristics and pharmacists' activities in this level of care.

The methodological approach is summarized in Figure 1.

Consensus methods can be defined as a set of facilitation techniques designed to explore the level of consensus among a group of experts by synthesizing and clarifying expert opinions. In healthcare research, four consensus methods are frequently used: Delphi, Nominal Group technique, Consensus Development Conference, and RAND/UCLA Appropriateness Method (RAM) [25,26]. RAM is accomplished from a list of predetermined items [27]. For this reason, RAM suits our objectives once Prescribing-Assessment Tools are already developed and published in the scientific literature. Generically, RAM methodology can be described in four main steps: (i) literature review; (ii) panel rating round to review the evidence gathered from literature (without any interactions between panelists, the silent round); (iii) face-to-face meeting aimed at discussing group's ratings, followed by individual opportunities for re-ratings; (iv) final classification of evidence as "appropriate", "uncertain" or "inappropriate" (according to panelists median scores) and discussion [27]. A pilot phase was undertaken to anticipate potential hinders in applying this method, particularly for the meeting step (e.g., time and other constraints). At this point, a RAM modification was assumed to strengthen a qualitative perspective on PATs use, inspired by a mixed-methods approach. Instead of a single round, two silent rounds with all panelists were conducted to obtain PATs quantitative appraisal before the face-to-face meeting. 


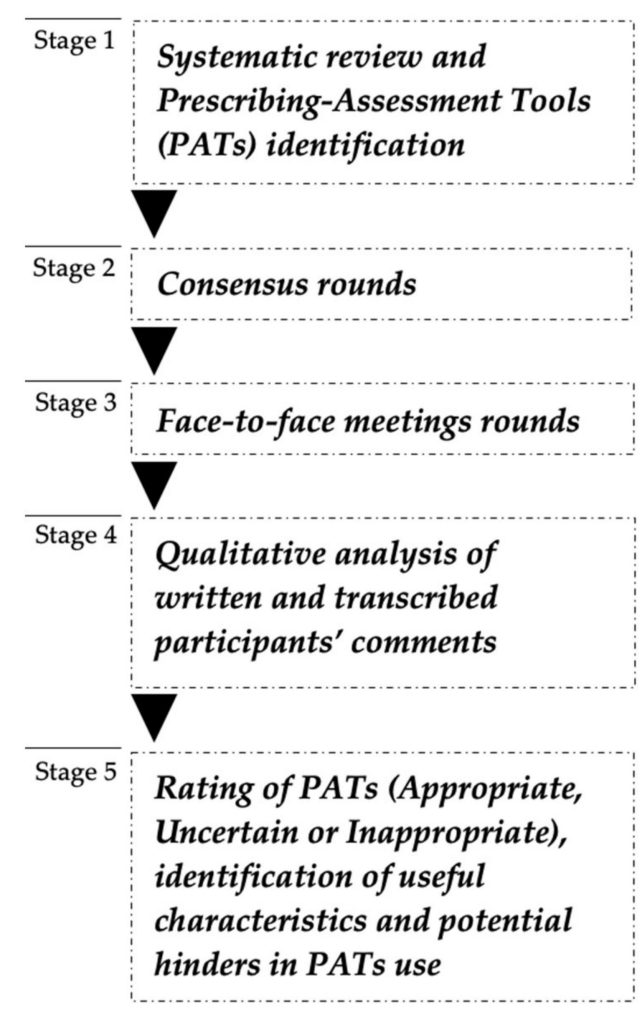

Figure 1. Study methodology flowchart.

\subsection{Literature Review and Prescribing-Assessment Tools Identification}

Prescribing-Assessment Tools were identified in studies reporting pharmacist-led interventions in institutional LTC settings from published primary sources summarized in a recent systematic review, published elsewhere (Figure 1) [28]. Additionally, a manual search of relevant references from the retrieved papers was undertaken.

\subsection{Prescribing-Assessment Tools Independent Rating}

Panelists' enrollment was made following a purposive sampling technique (Table 1). Panelists were LTC pharmacists exclusively dedicated to at least one of the three types of RNCCI inpatient settings ('Convalescence units', 'Medium Term \& Rehabilitation units', and 'Long-Term \& Maintenance units') or hospital pharmacists. Referral of patients to the National Network for Long-Term Integrated Care is made mainly through hospital settings; therefore, the intervention of hospital pharmacists in the transition of patients to LTC occurs. Community pharmacists are not involved in the transition of care; thus, they were not recruited. The final PATs collection was mailed to institutional addresses of each pharmacist for judgment and private rating, as described next.

Panelists were asked to rate each PAT regarding its suitability for LTC pharmacy practice (How appropriate could this PAT be in providing care to LTC patients?), using a 9-points Likert scale (1-totally inappropriate; 9-totally appropriate), and to comment on their ratings. Ratings of 1-3, 4-6 and 7-9 were classified as Inappropriate (I), Uncertain (B), and Appropriate (A), respectively. After each round, the group median rate, Disagreement Index (DI) and comments supporting ratings were anonymously shared with all panelists, who were allowed to change their ratings before the second round and face-to-face meeting.

Disagreement Index is an indicator of consensus and for its calculation, the following equation was used: DI = IPR/IPRAS (IPR, Inter-Percentile Range; IPRAS, InterPercentile Range Adjusted for Symmetry), considering the following: (i) IPR = 70th-30th percentile; (ii) IPR Central Point $(\mathrm{IPRCP}=(70$ th +30 th percentile $) / 2$; (iii) Asymmetry Index $(\mathrm{AI})=(5-\mathrm{IPRCP})$; (iv) IPRAS $=2,5+(\mathrm{AI} \times 1,5)$ [27]. A DI value less than or equal to 1 signals agreement between panelists [29]. 
Table 1. Panelists' demographic characteristics.

\begin{tabular}{cccc}
\hline Participant & Gender & Setting of Professional Activity & Years of Practice \\
\hline 1 & Female & Long-Term Care Facility & 10 \\
2 & Female & Long-Term Care Facility & 15 \\
3 & Female & Long-Term Care Facility & 5 \\
4 & Female & Long-Term Care Facility & 15 \\
5 & Female & Long-Term Care Facility & 11 \\
6 & Female & Long-Term Care Facility & 1 \\
7 & Female & Long-Term Care Facility & 3 \\
8 & Female & Long-Term Care Facility & 1 \\
9 & Female & Hospital & 3 \\
10 & Female & Hospital & 4 \\
11 & Male & Hospital & 5 \\
12 & Male & Hospital & 4 \\
13 & Male & Hospital & 24 \\
\hline
\end{tabular}

\subsection{Face-to-Face Meetings}

Live remote meetings were held with panelists after the two silent rounds to reach a consensus. An earlier pilot panel, meeting online with 3 LTC pharmacists, took $3 \mathrm{~h}$ and $15 \mathrm{~min}$ to its end. Thus, to assure that all participants could express their evaluation of all PATs, including qualitative accounts, within an acceptable timeframe, it was necessary to convene three groups of 3-5 panelists. All panels aimed to reach an agreement on assessing PATs as Appropriate, Uncertain and Inappropriate, regarding their usefulness for LTC pharmacy practice. In case panelists disagreed, that panel's rating was considered as Uncertain (B). For final consensus as Inappropriate (If), Uncertain (Bf), and Appropriate (Af), a thumb rule was followed: for PATs with at least two panels' rating aligned with the 2nd round overall rating and a DI equal or below 1, final consensus as If, Bf or Af was considered accordingly to the overall group's rating. If the two panels' ratings were not aligned with the overall group's rating, the PAT was classified as Uncertain (B) use for LTC pharmacy practice.

\subsection{Analysis of Panellists' Accounts and Final Classification}

To inform reasons for ratings and consensus and explore PATs' characteristics identified as more suitable for pharmacist LTC practice, a record of comments (written during the private rating and transcribed from face-to-face meetings) was performed. The panelists' accounts were interpreted, organized, and synthesized into two main themes (positive features and usage hinders) without pursuing a detailed qualitative analytical approach.

\section{Results}

\subsection{Literature Review}

The literature review process (Figure 2) retrieved 24 PATs (Supplementary Table S1). These were organized into different practice areas, namely: (i) anticholinergic and sedative medicines usage: ARS [30] and DBI [31]; (ii) hemorrhagic risk: ATRIA [32], CHA2DS2VASc [33], HAS-BLED [34] and HEMORR2HAGES [35]; (iii) antibiotics usage: Loeb [36]; iv) medication complexity: MRCI [37,38] and Mrs. GRACE [39]; (v) comprehensive implicit assessment of prescribing: MAI [40] and PAI [41]; (vi) comprehensive, explicit assessment of prescribing: Beers criteria [42]; NORGEP [43]; STOPP/START [44]; FORTA [45,46]; WinitWatjanas criteria [47]; Rancourts criteria [48]; Poudels criteria [49]; McLeods criteria [50]; Laroches criteria [51]; Australian Prescribing Indicators Tool [52] (vii) medicines usage in dementia: APID [53], Holmes criteria [54] and Krogers criteria [55]. 


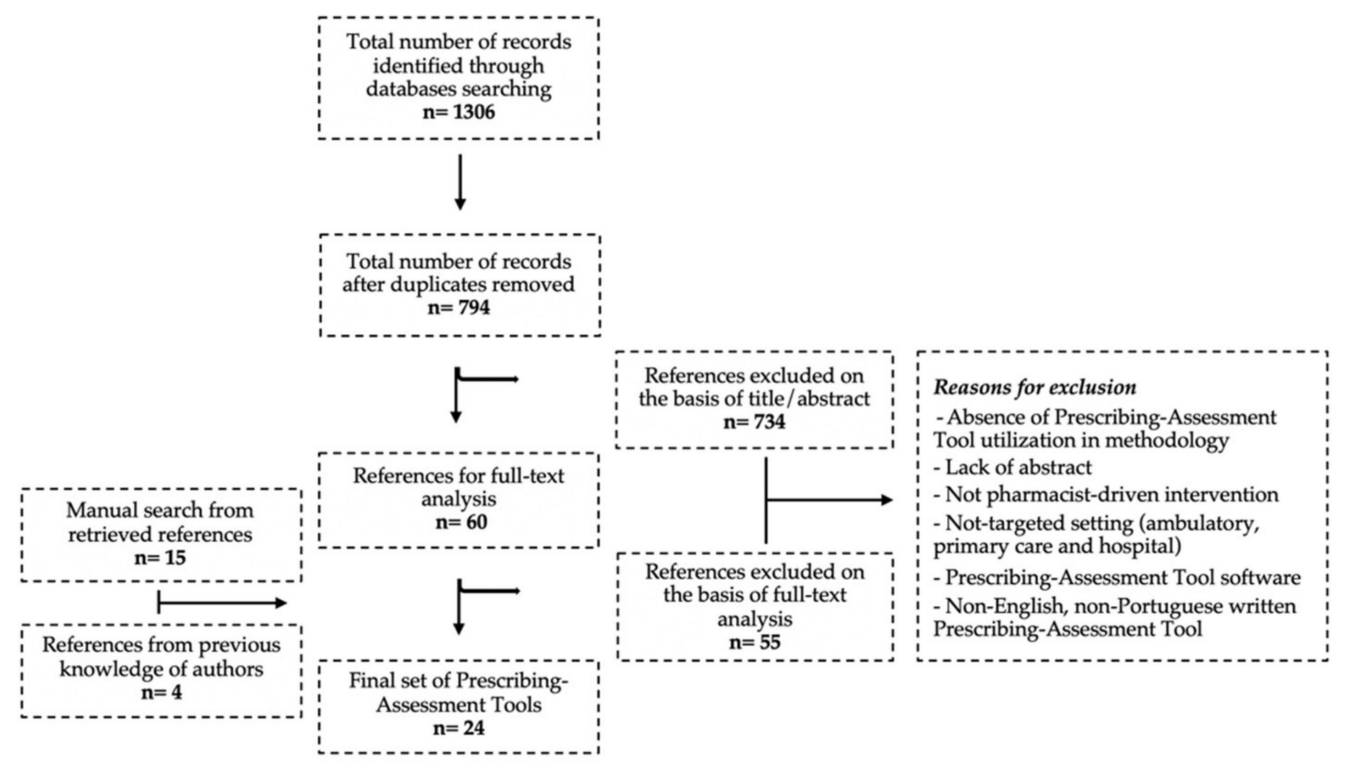

Figure 2. Flowchart of literature review and Prescribing-Assessment Tools identification.

\subsection{Panellists' Characteristics}

Participants' characteristics are described in Table 1. Participants enrolled included pharmacists working in Long-Term Care Facilities (LTCFs) or hospitals from four Regional Health Authorities (RHAs) catchment areas (out of 5 RAHs in mainland Portugal).

Three meetings with three panelists each were organized. The face-to-face panels were formed by participants 1, 2, 3 (panel 1-LTC pharmacists), 4, 5, 6 (panel 2-LTC pharmacists), 10, 11, 13 (panel 3-Hospital pharmacists), i.e., a dropout rate of 30\% was verified (participants 7,8 and 9).

\subsection{RAM Rounds, Face-to-Face Meetings and Final Consensus}

For 14 PATs, consensus was reached in all components, i.e., overall group rating (with $\mathrm{DI} \leq 1)$ was aligned with the three panels ratings. For instance, in the case of ATRIA, the second-round rating was 7 (A)-with a DI of 0.164 -and panels' 1, 2, and 3 ratings were A; thus, the final consensus was set as Af (Appropriate). For 10 PATs, one panel rating was not aligned with the rest of the ratings. For instance, in the case of DBI, the overall group's rating was C (Inappropriate) with a DI of 0.438; panels' 1 and 2 ratings were C, while panel's 3 rating was B; thus, the final decision was Cf (Inappropriate). For all PATs, DI at the second round was lower than 1. If this rule could not be followed, a PAT was rated for Uncertain (Bf) usefulness in LTC pharmacy practice. Results are summarized in Table 2. 
Table 2. Prescribing-Assessment Tools ratings, representative quotations and final consensus.

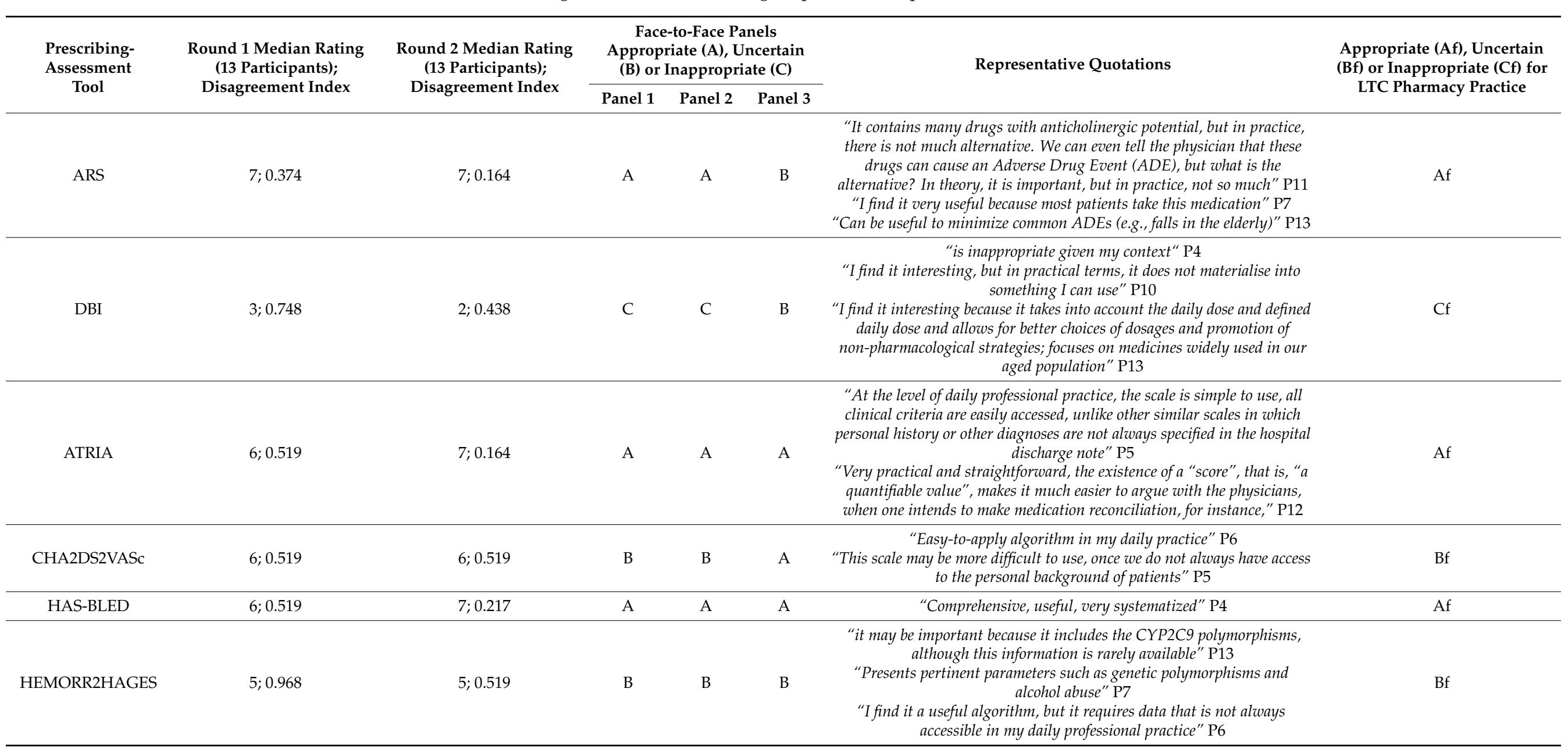


Table 2. Cont.

\begin{tabular}{|c|c|c|c|c|c|c|c|}
\hline \multirow{2}{*}{$\begin{array}{l}\text { Prescribing- } \\
\text { Assessment } \\
\text { Tool }\end{array}$} & \multirow{2}{*}{$\begin{array}{c}\text { Round } 1 \text { Median Rating } \\
\text { (13 Participants); } \\
\text { Disagreement Index }\end{array}$} & \multirow{2}{*}{$\begin{array}{c}\text { Round } 2 \text { Median Rating } \\
\text { (13 Participants); } \\
\text { Disagreement Index }\end{array}$} & \multicolumn{3}{|c|}{$\begin{array}{c}\text { Face-to-Face Panels } \\
\text { Appropriate (A), Uncertain } \\
\text { (B) or Inappropriate (C) }\end{array}$} & \multirow[t]{2}{*}{ Representative Quotations } & \multirow{2}{*}{$\begin{array}{c}\text { Appropriate (Af), Uncertain } \\
\text { (Bf) or Inappropriate (Cf) for } \\
\text { LTC Pharmacy Practice }\end{array}$} \\
\hline & & & Panel 1 & Panel 2 & Panel 3 & & \\
\hline Loeb criteria & $6 ; 1.04$ & $6 ; 0.652$ & $\mathrm{~A}$ & A & $\mathrm{C}$ & $\begin{array}{c}\text { "I consider an algorithm very adapted to the LTC reality in order to assess } \\
\text { the prescription of antibiotics for the most common infections" P5 } \\
\text { "It addresses the three main types of infection that we face daily and allows } \\
\text { you to screen the appropriateness of antibiotic prescription in a very quick } \\
\text { and simple way" P1 } \\
\text { "Not useful in a practical context, since clinical conditions are much more } \\
\text { complex than the algorithm reflects" P12 }\end{array}$ & $\mathrm{Bf}$ \\
\hline MRCI & $5 ; 1.70$ & $5 ; 0.702$ & B & B & B & $\begin{array}{c}\text { "Although time consuming, very interesting" } \mathrm{P} 2 \\
\text { "It is not feasible for a regular use due to its length" } \mathrm{P} 9 \\
\text { "Can be useful in the post-discharge moment; however, it is } \\
\text { not practical" } \mathrm{P} 5 \\
\text { "It would be very useful in my professional practice, since reducing the } \\
\text { complexity of the regimens will reduce potential medication errors, } \\
\text { increase adherence and reduce costs" P6 }\end{array}$ & $\mathrm{Bf}$ \\
\hline Mrs. Grace & $5 ; 0.997$ & $5 ; 0.997$ & B & B & B & $\begin{array}{c}\text { "Complete and with objective instructions for action" P10 } \\
\text { "Very interesting; however, I believe its implementation is hindered due to } \\
\text { the limited human resources available in LTC" P4 } \\
\text { "I find it very useful to use it in the planned discharges as a way to adapt } \\
\text { the therapeutic regimens individually to the patient and caregivers and as } \\
\text { a way to promote adherence to the therapeutic regimen" P3 } \\
\text { "the algorithm has little practical application since during patient staying } \\
\text { it is not always possible to "simplify" therapy due to having a pre-defined } \\
\text { drug formulary" P5 }\end{array}$ & $\mathrm{Bf}$ \\
\hline MAI & $7 ; 0.219$ & $8 ; 0.219$ & $\mathrm{~A}$ & B & $\mathrm{A}$ & $\begin{array}{c}\text { "Very adapted to pharmacists. I find it particularly useful for some } \\
\text { patients and not for everyone. It allows our participation in } \\
\text { multidisciplinary meetings to become more useful. It can be important in } \\
\text { deprescribing activities" P1 } \\
\text { "I find this algorithm very useful and easy to query. However, it is very } \\
\text { time-consuming as it is necessary to review each drug at ten different } \\
\text { points for each patient" P6 } \\
\text { "Interesting for therapeutic reconciliation, although these aspects are } \\
\text { already taken into account. It can serve more as a guide than for use } \\
\text { in practice" P4 }\end{array}$ & Af \\
\hline
\end{tabular}


Table 2. Cont.

\begin{tabular}{|c|c|c|c|c|c|c|c|}
\hline \multirow{2}{*}{$\begin{array}{l}\text { Prescribing- } \\
\text { Assessment } \\
\text { Tool }\end{array}$} & \multirow{2}{*}{$\begin{array}{c}\text { Round } 1 \text { Median Rating } \\
\text { (13 Participants); } \\
\text { Disagreement Index }\end{array}$} & \multirow{2}{*}{$\begin{array}{c}\text { Round } 2 \text { Median Rating } \\
\text { (13 Participants); } \\
\text { Disagreement Index }\end{array}$} & \multicolumn{3}{|c|}{$\begin{array}{c}\text { Face-to-Face Panels } \\
\text { Appropriate (A), Uncertain } \\
\text { (B) or Inappropriate (C) }\end{array}$} & \multirow[t]{2}{*}{ Representative Quotations } & \multirow{2}{*}{$\begin{array}{l}\text { Appropriate (Af), Uncertain } \\
\text { (Bf) or Inappropriate (Cf) for } \\
\text { LTC Pharmacy Practice }\end{array}$} \\
\hline & & & Panel 1 & Panel 2 & Panel 3 & & \\
\hline $\begin{array}{l}\text { Australian } \\
\text { Prescribing } \\
\text { Indicators Tool }\end{array}$ & $3 ; 0.561$ & $3 ; 0.519$ & $\mathrm{C}$ & $\mathrm{C}$ & $\mathrm{B}$ & $\begin{array}{c}\text { "Time-consuming, and its use may not always be feasible. Contains very } \\
\text { useful information for my technical-scientific development" P13 } \\
\text { "It is a too lengthy PAT" P9 } \\
\text { "I consider this PAT impractical to consult due to its organization by } \\
\text { statements and not by medications, physiological systems or } \\
\text { therapeutic classes" P6 }\end{array}$ & $\mathrm{Cf}$ \\
\hline Beers criteria & $7 ; 0.292$ & $7 ; 0.292$ & A & $\mathrm{A}$ & A & $\begin{array}{l}\text { "Quite adequate to the reality of LTC. Although it is the best known } \\
\text { among health professionals and this implies that the prescriptions are very } \\
\text { much in line with this criterion, I believe its use is fundamental" P1 } \\
\text { "Very useful, just missing the suggestion of alternative" P4 }\end{array}$ & Af \\
\hline FORTA & $7 ; 0.000$ & $7 ; 0.09$ & $\mathrm{~A}$ & $\mathrm{~A}$ & $\mathrm{~A}$ & $\begin{array}{c}\text { "Good instrument for medication review in the elderly and based on } \\
\text { a diagnosis. Facilitator of doctor-pharmacist and } \\
\text { nurse-pharmacist interactions" P13 } \\
\text { "Very organized and quick and easy to consult" P2 }\end{array}$ & Af \\
\hline Laroche criteria & $7 ; 0.000$ & $7 ; 0.000$ & $\mathrm{~A}$ & $\mathrm{~A}$ & $\mathrm{~A}$ & $\begin{array}{c}\text { "Very useful and easy to apply in my daily professional practice. Its main } \\
\text { advantage is the fact that it presents the reasons for non-suitability and } \\
\text { what are the safest alternatives" P6 } \\
\text { "It has a good compromise between extension, reasons and alternatives" P3 }\end{array}$ & Af \\
\hline McLeod criteria & $6 ; 0.217$ & $6 ; 0.217$ & $\mathrm{~A}$ & B & B & $\begin{array}{c}\text { "I appreciate this PAT because it offers alternatives, the risk associated to } \\
\text { PIMs and the statistics about the consensus" P9 } \\
\text { "It is organized by incorrect practice and not by medication; it is not so } \\
\text { direct, it is less practical" P10 } \\
\text { "It can be difficult to consult, but it is useful to suggest therapeutic } \\
\text { alternatives to prescribers" P2 }\end{array}$ & $\mathrm{Bf}$ \\
\hline NORGEP & $3 ; 0.652$ & $3 ; 0.652$ & $\mathrm{C}$ & $\mathrm{C}$ & $\mathrm{C}$ & $\begin{array}{l}\text { "It didn't seem very useful to me due to its sparse coverage" P4 } \\
\text { "Little information compared to other criteria" P11 }\end{array}$ & $\mathrm{Cf}$ \\
\hline Poudel criteria & $8 ; 0.292$ & $8 ; 0.292$ & $\mathrm{~A}$ & $\mathrm{~A}$ & $\mathrm{~A}$ & $\begin{array}{c}\text { "This PAT is very interesting because it has indications for withdrawal } \\
\text { regimens, in addition to therapeutic alternatives" P2 } \\
\text { "It complements the Beers criteria by presenting suggestions of drug } \\
\text { tapering. Moreover, it presents therapeutic alternatives, similar to } \\
\text { Laroche's criteria" P12 }\end{array}$ & Af \\
\hline
\end{tabular}


Table 2. Cont

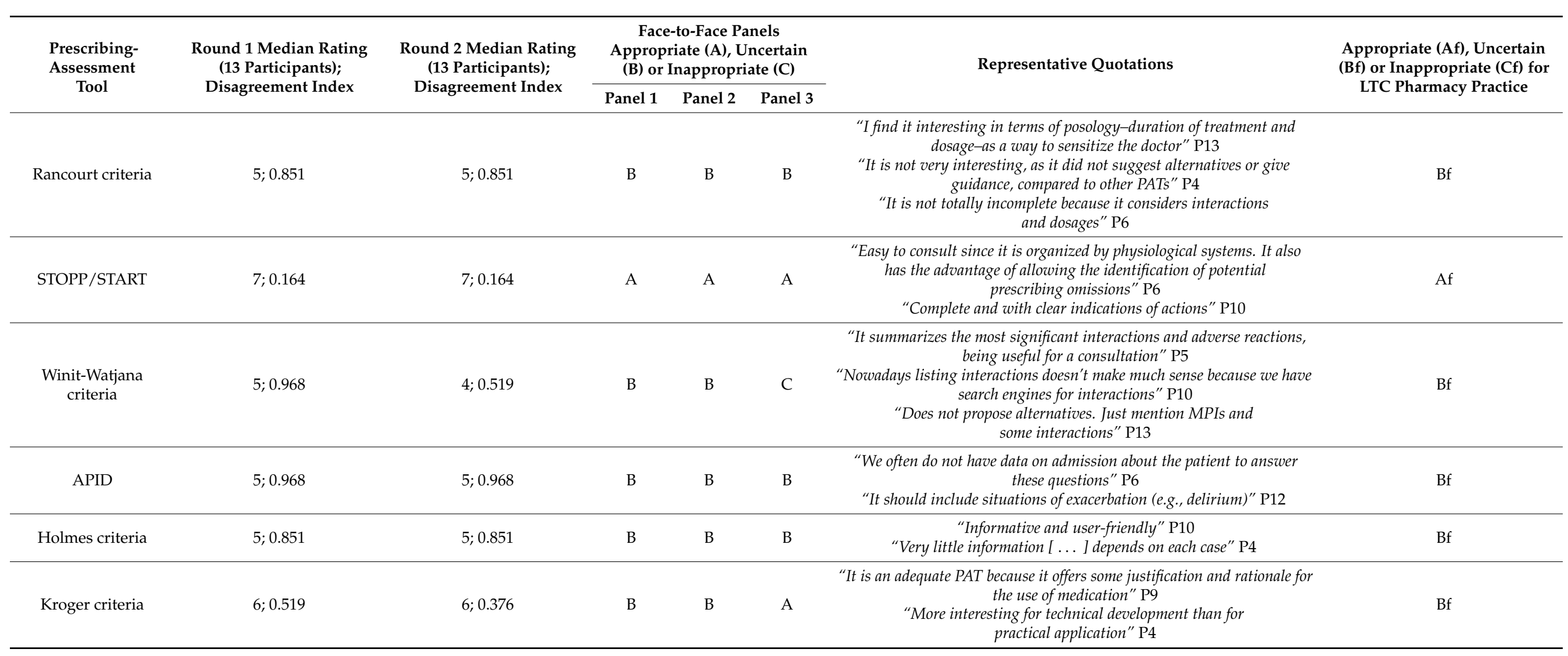




\subsection{Relevant Characteristics of PATs}

Several characteristics of interest emerged from comments and face-to-face meetings qualitative analysis (Table 3).

Table 3. Prescribing-Assessment Tools' useful characteristics and representative quotations.

Prescribing-Assessment Tools'
Useful Characteristic

Levels of evidence

\section{Representative Quotations}

[FORTA] because it is organized by level of evidence (P7)

[... ] having the advantage of presenting the level of evidence (P8, on Beers')

I consider it a very complete and valuable criterion as it considers factors such as dose and duration of treatment (P8 on Rancourt's)

Dose and duration of treatment

I find it very interesting because it considers daily dose and allows to choose better posology (P13, on DBI's)

Useful because it gives a maximum of days, and many times physicians want to use antibiotics more days than those preconized (P3, on Loeb's)

\begin{tabular}{cc} 
Scoring system & $\begin{array}{r}\text { more days than those preconized (P3, on Loeb's) } \\
\text { [.. score", i.e., a quantifiable value, greatly facilitates discussion with physicians when } \\
\text { delivering therapeutic reconciliation, for example (P12, on ATRIA's) }\end{array}$ \\
\hline Reasons for PIM classification & $\begin{array}{c}\text { Contains very useful information such as reasons for PIM classification (P13, on Laroche's) } \\
\text { Presents the reasons why the medicine is potentially inappropriate (P8, on Beers') }\end{array}$
\end{tabular}

Very useful, only the suggestion of alternatives is missing (P4, on Beers') suggests therapeutic alternatives (P1, on Laroche's)

It is a helpful PAT because it suggests therapeutical alternatives (P9, on Laroche's)

$[\ldots]$ suggests therapeutical alternative $[. .$.$] (P5, on McLeod's)$

[... ] it offers therapeutical alternatives [ ... ] (P9, on McLeod's)

Inclusion of alternatives to PIMs

[... ] presents therapeutical alternatives, similarly to Laroche's (P12, on Poudel's)

It does not suggest alternatives; just mention PIMs and interactions

(P13, on Winit-Watjana's)

[... ] a helpful PAT should include therapeutical alternatives (P3, McLeod)

Contains valuable information such as alternative medicines (P13, on Laroche's) It suggests therapeutical alternatives (P13, on Poudel's)

It does not have alternatives; I consider it a "lower version" (P12, on Winit-Watjana's)

I consider this criterion more complex to consult because it is organized by inappropriate practice and not by medicine, therapeutic indication, or physiological system (P8, on McLeod's)

I prefer a tool that evaluates by pharmacotherapeutic group and not so much by pathology

Organised by medicines groups because when I'm evaluating a prescription, I evaluate medicine by medicine and, if a question arises, it will help me to have a PAT by the pharmacotherapeutic group to consult and preferably, with alternatives in case you find something wrong (P10)

A PAT organized by pharmacotherapeutic groups helps more; it makes it simpler (P13) It seemed to be the most organized as it is divided into therapeutic groups (P3, on McLeod's) Easy to consult as it is organized by therapeutic groups (P2, on Poudel's)

Inclusion of risk associated with PIM

Organised by disease/syndrome

Consensus on PIM/alternative

Withdrawal regimens
I find this PAT interesting because it mentions the risk to the patient (P5, on McLeod's) It includes the risk to the patient [ ... ] (P9, on McLeod's) It has the risk associated with the patient (P3, McLeod's)

I prefer a disease-oriented PAT (P11)

It includes the most prevalent diseases on the LTC national network (P1, on FORTA's)

It includes the panel agreement on the PIM alternative (P5, on McLeod's)

It includes statistics about the consensus on the use of a particular medicine (P9, on McLeod's)

It has indications on how to withdraw the PIM, being a differentiating factor from the other PATs (P5, on Poudel's)

In a way, it complements the Beers' criteria, as it suggests withdrawal regimens (P12, on Poudel's)

It suggests withdrawal regimens (P13, on Poudel's) 
Four main groups of potential determinants hindering the use of PATs have also been identified through qualitative analysis (Table 4).

Table 4. Potential determinants hindering Prescribing-Assessment Tool use.

\begin{tabular}{|c|c|}
\hline Potential PATs Use Hinders & Representative Quotations \\
\hline Lack of time / Lack of pharmacists & $\begin{array}{r}\text { Challenging to use considering the low human resources ratio in LTC (P4, on DBI's) } \\
\text { I think this PAT would be very useful [ ... ] The main limitation is related to the time spent in } \\
\text { its application (P8, on Mrs. Grace's) } \\
\text { I consider it very useful in my daily professional practice as it is complete [ ... ] however, it is } \\
\text { a very time-consuming PAT to apply as it is necessary to review each medicine of each patient } \\
\text { at ten different points (P8, on MAI's) } \\
\text { The amount and turnover of patients does not allow us to look detailed at every prescription } \\
\text { using some of these PATs (P1) }\end{array}$ \\
\hline Assistance to several units & $\begin{array}{c}\text { It is not easy to apply in my daily professional practice because it involves discussing these } \\
\text { situations with the clinical team when prescribing, and I am not present full time at } \\
\text { the facilities (P8, on Loeb's) } \\
\text { It is not possible to use it for all prescriptions since there are daily therapeutic changes in the } \\
\text { various facilities that I assist, and most of the time, I'm not at the facilities when new } \\
\text { prescriptions occur (P3, on PAI's) }\end{array}$ \\
\hline $\begin{array}{l}\text { Communication barriers with the } \\
\text { healthcare team }\end{array}$ & $\begin{array}{c}\text { Despite the quality and usefulness of PATs, the difficulty can come from the physicians because } \\
\text { they hardly listen to the pharmacist's opinion (P2) }\end{array}$ \\
\hline $\begin{array}{l}\text { Limited access or availability } \\
\text { of information }\end{array}$ & $\begin{array}{l}\text { We often do not have information to use this PAT because the physician usually does not } \\
\text { register this data, and we do not have access to the entire clinical file (P13, on Loeb's) } \\
\text { We often don't have access to patients' background or is not even available from the transition } \\
\text { of care (P5, on HAS-BLED's / HEMORR2HAGES') } \\
\text { Sometimes I don't have access to some clinical data (e.g., liver function tests) } \\
\text { (P8, on HAS-BLED's / HEMORR2HAGES') }\end{array}$ \\
\hline
\end{tabular}

\section{Discussion}

This study aimed at identifying useful Prescribing-Assessment Tools for LTC pharmacy practice and, additionally, to map its most relevant characteristics and potential hinders.

LTC pharmacy practice varies regarding the population served and patients' characteristics (e.g., units exclusively dedicated to cognitive disorders) and pharmacist presence (on-site vs. periodic visits $[4,56]$. For these reasons, identifying PATs that might be useful for all LTC pharmacists and in the transition of care of LTC patients (hospital-LTC facility) may be difficult. Nevertheless, the RAND methodology allowed to reach a consensus on the most suitable tools for LTC pharmacy practice and mapped its most valuable characteristics. The number and diversity of enrolled participants (e.g., varying years of experience) enriched the discussion and strengthened the potential to translate conclusions into practice. This study is the first to use the RAND approach in LTC pharmacy practice research to the best of our knowledge.

Inappropriate prescribing has been studied and published in the scientific literature for many decades; thus, tools addressing this topic have a considerable number. Kaufmann et al. systematic review identified 46 PATs, of which $6(13 \%)$ were initially developed for LTC use [20]. Similarly, Masnoon et al. identified 42 tools for assessment of the appropriateness of prescribing [19]. To address the apparent scarcity of PATs specifically designed for LTC, we have decided to identify PATs previously used in the LTC context [28]. Additionally, we tried to reduce the set of PATs for panelists' assessment to avoid loss of richness during meeting discussions.

The 24 PATs were grouped into seven areas: anticholinergic and sedative medicines; hemorrhagic risk; antibiotics; medication complexity; dementia; comprehensive assessment of prescribing (implicit or explicit). 
Participants reported anticholinergic and sedative medicines usage and hemorrhagic risk as relevant in the LTC pharmacy context. Scoring systems estimating the risk of bleeding in patients on anticoagulation, such as HAS-BLED and ATRIA, were classified as "Appropriate", while CHA2DS2VASc and HEMORR2HAGES were classified as "Uncertain". The difference in classification here seemed to be based on the nature and availability of the data needed to calculate the risk, like CYP 2C9 polymorphisms or previous diagnoses, often not available during the transition of care (e.g., history of alcohol abuse).

Pharmacists working in LTC facilities or hospitals expectably disagree on antibiotic use, knowing antibiotics' range and use differ in both settings. In RNCCI facilities, antibiotic use is often empirical (i.e., not assisted by antibiogram), while some antibiotics are exclusive of hospital use. In the rating of this particular PAT, hospital and LTC pharmacy practice differences were highlighted, with hospital pharmacists' panel rating it as "Inappropriate" and both LTC pharmacists' panels as "Appropriate". Nevertheless, if considering only LTC practice and excluding transition of care, Loeb's criteria seem appropriate.

Pharmacists identified some strengths on PATs for medication complexity, yet its usefulness seemed limited. Both MRCI and MRS.GRACE were rated as "Uncertain" for their usefulness for LTC pharmacy practice, mainly given its length (i.e., too timeconsuming). However, participants consider these tools as potentially useful at postdischarge moments and to ease medicines administration burden by nurses [57,58].

Prescribing-Assessment Tools targeted to medicines optimization in dementia (APID, Holmes's criteria, and Kroger's criteria) were all classified as "Uncertain". The usefulness of these PATs seems to considerable differ based on pharmacists' experiences with delivering care to patients with dementia or not. Further research on PATs in dementia is recommended, mainly due to the high prevalence of dementia and cognitive disorders amongst LTC patients $[59,60]$.

Prescribing-Assessment Tools not targeted to a disease/syndrome or a medicines group comprised $50 \%$ of all PATs assessed ( $n=12$ out of 24 ). PATs used for a comprehensive assessment of prescribing were divided into explicit and implicit. Explicit criteria represent the larger group $(\mathrm{n}=10)$, with Beers', Laroche's, and Poudel's criteria, FORTA and STOPP/START being classified as "Appropriate" for LTC pharmacy practice. Medication Appropriateness Index (implicit PAT) was also assessed as "Appropriate" by participants.

Explicit criteria (including ARS, ATRIA and HAS-BLED) represent $90 \%$ of all PATs classified as "Appropriate" ( $n=8$ out of 9 ), aligned with healthcare professionals' preferences reported in the scientific literature [61,62].

Agreement on the rating was reached for all PATs, and the combination of silent ratings and face-to-face discussion allows us to say that the 9 PATs rated as "Appropriate $[30,32,34,40,42,44,45,49,51]$ have the potential to be suitable for LTC pharmacy practice" and during the transition of care of LTC patients. All the 9 PATs address misprescribing, underprescribing and overprescribing practices included in the Potentially Inappropriate Prescribing concept.

In what concerns to helpful characteristics of PATs, the indication of alternatives to PIM seems to be one of the most relevant characteristics along with an organization by medicine, followed by the indication of recommended dose and duration of treatment. However, regarding PAT's organization (by medicine vs. by disease), further research is needed to explore more clearly participants' divide: "I prefer a tool that evaluates [medication] by pharmacotherapeutic group and not so much by pathology because when I'm evaluating a prescription, I evaluate medicine by medicine" (P10) vs. "I prefer a disease-oriented PAT" (P11). On the other hand, lack of time and staff (pharmacists) and limited availability or access to clinical information seems to be the most relevant hinders for PATs use in daily practice.

Some limitations of the study can be mentioned: (i) with exception to Beer's and MRCI, all PATs are not translated to Portuguese language or no previous validation or adaptation to Portuguese LTC context or medicines use, which may have had an impact on panelists' assessment; (ii) around $40 \%$ of PATs under evaluation are targeted to aged people, 
and LTC is not exclusively targeted to aged people, although, in $2020,83 \%$ of patients assisted in Portuguese LTC network were 65 years old or over [4]; (iii) other published PATs were not included in the final PATs set for analysis once the methodological strategy; (iv) given the heterogeneity of LTC worldwide and that participants work exclusively in Portugal, application of conclusions in international contexts may be hampered.

\section{Conclusions}

Nine Prescribing-Assessment Tools seem to be suitable in assisting clinical pharmacists' activities targeted to LTC patients. Except for one (MAI), all PATs identified are explicit criteria (ARS, ATRIA, HAS-BLED, Beers', FORTA, Laroche's, Poudel's, and STOPP/START criteria). These Prescribing-Assessment Tools seem to have the potential to be helpful for LTC patients during the transition of care. Three Prescribing-Assessment Tools were classified as Inappropriate for LTC pharmacy practice (DBI, Australian Prescribing Indicators, and NORGEP). Half of Prescribing-Assessment Tools were classified as "Uncertain", yet further studies should investigate their relevance in particular areas and circumstances of LTC pharmacy practice (e.g., medication regimen complexity or dementia). Explicit criteria gathered the preference of participants, in line with preferences reported in scientific literature. Some important design characteristics of Prescribing-Assessment Tools seem to be related to convenient features of these tools, such as indicating alternatives to Potentially Inappropriate Medication. Future research should investigate the impact of these PATs in relevant endpoints and outcomes for LTC patients (e.g., mortality, hospitalization).

Supplementary Materials: The following are available online at https:/ / www.mdpi.com/article/10 .3390 / pharmacy9040194/s1, Table S1: Summary of the identified Prescribing-Assessment Tools.

Author Contributions: Conceptualization: J.R.G., B.L.S., M.J.L., A.M.C.; Methodology: J.R.G.; Data collection: J.R.G., A.M.C.; Analysis: J.R.G., B.L.S., M.J.L., A.M.C.; Draft preparation: J.R.G.; Review and editing: J.R.G., B.L.S., A.M.C.; Supervision: B.L.S., M.J.L., A.M.C. All authors have read and agreed to the published version of the manuscript.

Funding: This research received no external funding.

Institutional Review Board Statement: The study was conducted according to the guidelines of the Declaration of Helsinki and approved by the Committee of Research involving Human Beings of the Faculty of Pharmacy of the University of Lisbon (no. 02/2020).

Informed Consent Statement: Informed consent was obtained from all subjects involved in the study.

Conflicts of Interest: The authors declare no conflict of interest.

\section{References}

1. World Health Organization. Towards an International Consensus on Policy for Long-Term Care of the Ageing. WHO. 2000. Available online: https:/ /apps.who.int/iris/handle/10665/66339 (accessed on 3 August 2021).

2. OECD. A Good Life in Old Age? Monitoring and Improving Quality in Long-Term Care. OECD; June 2013 (OECD Health Policy Studies). Available online: https://www.oecd-ilibrary.org/social-issues-migration-health/a-good-life-in-old-age_9789264194 564-en (accessed on 5 August 2021).

3. Lopes, H.; Mateus, C.; Hernández-Quevedo, C. Ten Years after the Creation of the Portuguese National Network for Long-Term Care in 2006: Achievements and Challenges. Health Policy 2018, 122, 210-216. [CrossRef] [PubMed]

4. Saúde, M.D. Monitorização da Rede Nacional de Cuidados Continuados Integrados (RNCCI)—2020. 2020. Available online: http:/ / www. acss.min-saude.pt/wp-content/uploads /2021/08/Relatorio-de-Monitorizaç\{ $\{$ a\}\}o-da-RNCCI-Anual-2020-VF.pdf (accessed on 4 August 2021).

5. Nobili, A.; Garattini, S.; Mannucci, P.M. Multiple Diseases and Polypharmacy in the Elderly: Challenges for the Internist of the Third Millennium. J. Comorbidity 2011, 1, 28-44. [CrossRef] [PubMed]

6. Nunes, B.P.; Flores, T.R.; Mielke, G.; Thumé, E.; Facchini, L.A. Multimorbidity and mortality in older adults: A systematic review and meta-analysis. Arch. Gerontol. Geriatr. 2016, 67, 130-138. [CrossRef] [PubMed]

7. Khezrian, M.; McNeil, C.J.; Murray, A.; Myint, P.K. An overview of prevalence, determinants and health outcomes of polypharmacy. Ther. Adv. Drug Saf. 2020, 11. [CrossRef]

8. Gray, S.L.; Marcum, Z.A.; Schmader, K.E.; Hanlon, J.T. Update on Medication Use Quality and Safety in Older Adults, 2017. J. Am. Geriatr. Soc. 2018, 66, 2254-2258. [CrossRef] 
9. McLean, A.J.; le Couteur, D.G. Aging biology and geriatric clinical pharmacology. Pharmacol. Rev. 2004, 56, 163-184. [CrossRef]

10. Guaraldo, L.; Cano, F.G.; Damasceno, G.S.; Rozenfeld, S. Inappropriate medication use among the elderly: A systematic review of administrative databases. BMC Geriatr. 2011, 11, 79. [CrossRef]

11. Avorn, J.; Gurwitz, J.H. Drug Use in the Nursing Home. 1995. Available online: http:/ / annals.org/ (accessed on 3 August 2021).

12. Qassemi, S.; Pagès, A.; Rouch, L.; Bismuth, S.; Stillmunkes, A.; Lapeyre-Mestre, M.; McCambridge, C.; Cool, C.; Cestac, P. Potentially Inappropriate Drug Prescribing in French Nursing Home Residents: An Observational Study. Pharmacy 2020, 8, 133. [CrossRef]

13. Storms, H.; Marquet, K.; Aertgeerts, B.; Claes, N. Prevalence of inappropriate medication use in residential long-term care facilities for the elderly: A systematic review. Eur. J. Gen. Pract. 2017, 23, 69-77. [CrossRef]

14. Spinewine, A.; Schmader, K.E.; Barber, N.; Hughes, C.; Lapane, K.L.; Swine, C.; Hanlon, J.T. Appropriate prescribing in elderly people: How well can it be measured and optimised? Lancet 2007, 370, 173-184. [CrossRef]

15. Cahir, C.; Bennett, K.; Teljeur, C.; Fahey, T. Potentially inappropriate prescribing and adverse health outcomes in community dwelling older patients. Br. J. Clin. Pharmacol. 2014, 77, 201-210. [CrossRef]

16. Rankin, A.; Cadogan, C.A.; Patterson, S.M.; Kerse, N.; Cardwell, C.R.; Bradley, M.C.; Ryan, C.; Hughes, C. Interventions to improve the appropriate use of polypharmacy for older people. Cochrane Database Syst. Rev. 2018, 9. [CrossRef]

17. O'connor, M.N.; Gallagher, P.; O'mahony, D. Inappropriate Prescribing Criteria, Detection and Prevention. Drugs Aging 2012, 29, 437-452. [CrossRef]

18. O'Mahony, D.; Gallagher, P.F.; Lavan, A.H. Methods to reduce prescribing errors in elderly patients with multimorbidity. Clin. Interv. Aging 2016, 11, 857-866. [CrossRef]

19. Masnoon, N.; Shakib, S.; Ellett, L.K.; Caughey, G. Tools for Assessment of the Appropriateness of Prescribing and Association with Patient-Related Outcomes: A Systematic Review. Drugs Aging 2018, 35, 43-60. [CrossRef]

20. Kaufmann, C.P.; Tremp, R.; Hersberger, K.E.; Lampert, M.L. Inappropriate prescribing: A systematic overview of published assessment tools. Eur. J. Clin. Pharmacol. 2013, 70, 1-11. [CrossRef]

21. Scahill, S.; Atif, M.; Babar, Z. Defining pharmacy and its practice: A conceptual model for an international audience. Integr. Pharm. Res. Pract. 2017, 6, 121-129. [CrossRef]

22. Wiedenmayer, K.; Summers, R.S.; Mackie, C.A.; Gous, A.G.S.; Everard, M.; Tromp, D. Developing Pharmacy Practice: A Focus on Patient Care, 1st ed.; World Health Organization (International Pharmaceutical Federation): Hague, The Netherlands, 2006. Available online: https:/ / apps.who.int/iris/bitstream/handle/10665/69399/WHO_PSM_PAR_2006.5_eng.pdf?sequence=1\& isAllowed =y (accessed on 1 November 2021).

23. Sanford, A.M.; Orrell, M.; Tolson, D.; Abbatecola, A.M.; Arai, H.; Bauer, J.M.; Cruz-Jentoft, A.J.; Dong, B.; Ga, H.; Goel, A.; et al. An International Definition for "Nursing Home". J. Am. Med. Dir. Assoc. 2015, 16, 181-184. [CrossRef]

24. World Health Organization—Regional Office for Europe. Integrated Care Models: An Overview Working Document. 2016. Available online: http:/ / www.euro.who.int/pubrequest (accessed on 3 August 2021).

25. Campbell, S.M.; Cantrill, J.A. Consensus methods in prescribing research. J. Clin. Pharm. Ther. 2001, 26, 5-14. [CrossRef]

26. Humphrey-Murto, S.; Varpio, L.; Wood, T.J.; Gonsalves, C.; Ufholz, L.A.; Mascioli, K.; Wang, C.; Foth, T. The Use of the Delphi and Other Consensus Group Methods in Medical Education Research: A Review. Acad. Med. 2017, 92, 1491-1498. [CrossRef]

27. Fitch, K.; Bernstein, S.; Aguilar, M.; Burnand, B. The Rand/UCLA Appropriateness Method User's Manual; RAND: Santa Monica, CA, USA, 2001.

28. Gonçalves, J.R.; Ramalhinho, I.; Sleath, B.L.; Lopes, M.J.; Cavaco, A.M. Probing pharmacists' interventions in Long-Term Care: A systematic review. Eur. Geriatr. Med. 2021, 12, 673-693. [CrossRef]

29. Din, S.; Kent, A.; Pollok, R.C.; Meade, S.; Kennedy, N.A.; Arnott, I.; Beattie, R.M.; Chua, F.; Cooney, R.; Dart, R.J.; et al. Adaptations to the British Society of Gastroenterology guidelines on the management of acute severe UC in the context of the COVID-19 pandemic: A RAND appropriateness panel. Gut 2020, 69, 1769-1777. [CrossRef]

30. Rudolph, J.L.; Salow, M.J.; Angelini, M.C.; McGlinchey, R.E. The Anticholinergic Risk Scale and Anticholinergic Adverse Effects in Older Persons. Arch. Intern. Med. 2008, 168, 508-513. [CrossRef]

31. Hilmer, S.N.; Mager, D.E.; Simonsick, E.M.; Cao, Y.; Ling, S.M.; Windham, B.G.; Harris, T.B.; Hanlon, J.T.; Rubin, S.M.; Shorr, R.I.; et al. A Drug Burden Index to Define the Functional Burden of Medications in Older People. Arch. Intern. Med. 2007, 167, 781-787. [CrossRef]

32. Fang, M.C.; Go, A.S.; Chang, Y.; Borowsky, L.H.; Pomernacki, N.K.; Udaltsova, N.; Singer, D.E. A New Risk Scheme to Predict Warfarin-Associated Hemorrhage: The ATRIA (Anticoagulation and Risk Factors in Atrial Fibrillation) Study. J. Am. Coll. Cardiol. 2011, 58, 395-401. [CrossRef]

33. Lip, G.Y.; Nieuwlaat, R.; Pisters, R.; Lane, D.A.; Crijns, H.J. Refining clinical risk stratification for predicting stroke and thromboembolism in atrial fibrillation using a novel risk factor-based approach: The Euro Heart Survey on atrial fibrillation. Chest 2010, 137, 263-272. [CrossRef]

34. Pisters, R.; Lane, D.A.; Nieuwlaat, R.; De Vos, C.B.; Crijns, H.J.; Lip, G.Y. A novel user-friendly score (HAS-BLED) to assess 1-year risk of major bleeding in patients with atrial fibrillation: The euro heart survey. Chest 2010, 138, 1093-1100. [CrossRef]

35. Gage, B.F.; Yan, Y.; Milligan, P.; Waterman, A.; Culverhouse, R.; Rich, M.W.; Radford, M. Clinical classification schemes for predicting hemorrhage: Results from the National Registry of Atrial Fibrillation (NRAF). Am. Heart J. 2006, 151, 713-719. [CrossRef] 
36. Loeb, M.; Bentley, D.W.; Bradley, S.; Crossley, K.; Garibaldi, R.; Gantz, N.; McGeer, A.; Muder, R.R.; Mylotte, J.; Nicolle, L.E.; et al. Development of Minimum Criteria for the Initiation of Antibiotics in Residents of Long-Term-Care Facilities: Results of a Consensus Conference. Infect. Control. Hosp. Epidemiol. 2001, 22, 120-124. [CrossRef]

37. George, J.; Phun, Y.-T.; Bailey, M.J.; Kong, D.C.; Stewart, K. Development and Validation of the Medication Regimen Complexity Index. Ann. Pharmacother. 2004, 38, 1369-1376. [CrossRef]

38. Melchiors, A.C.; Correr, C.J.; Fernández-Llimos, F. Translation and Validation into Portuguese Language of the Medication Regimen Complexity Index. Arq Bras Cardiol. 2007, 89, 210-218. [CrossRef] [PubMed]

39. Chen, E.Y.; Sluggett, J.; Ilomaki, J.; Hilmer, S.; Corlis, M.; Picton, L.J.; Dean, L.; Alderman, C.P.; Farinola, N.; Gailer, J.; et al. Development and validation of the Medication Regimen Simplification Guide for Residential Aged CarE (MRS GRACE). Clin. Interv. Aging 2018, 13, 975-986. [CrossRef] [PubMed]

40. Hanlon, J.T.; Schmader, K.E.; Samsa, G.P.; Weinberger, M.; Uttech, K.M.; Lewis, I.K.; Cohen, H.J.; Feussner, J.R. A method for assessing drug therapy appropriateness. J. Clin. Epidemiol. 1992, 45, 1045-1051. [CrossRef]

41. Tully, M.P.; Javed, N.; Cantrill, J.A. Development and Face Validity of Explicit indicators of Appropriateness of Long Term Prescribing. Pharm. World Sci. 2005, 27, 407-413. [CrossRef]

42. Fick, D.M.; Semla, T.P.; Steinman, M.; Beizer, J.; Brandt, N.; Dombrowski, R.; DuBeau, C.E.; Pezzullo, L.; Epplin, J.J.; Flanagan, N. American Geriatrics Society 2019 Updated AGS Beers Criteria® ${ }^{\circledR}$ for Potentially Inappropriate Medication Use in Older Adults. J. Am. Geriatr. Soc. 2019, 67, 674-694.

43. Rognstad, S.; Brekke, M.; Fetveit, A.; Spigset, O.; Wyller, T.B.; Straand, J. The Norwegian General Practice (NORGEP) criteria for assessing potentially inappropriate prescriptions to elderly patients. Scand. J. Prim. Health Care 2009, 27, 153-159. [CrossRef]

44. O'Mahony, D.; O'Sullivan, D.; Byrne, S.; O'Connor, M.N.; Ryan, C.; Gallagher, P. STOPP/START criteria for potentially inappropriate prescribing in older people: Version 2. Age Ageing 2015, 44, 213-218. [CrossRef]

45. Kuhn-Thiel, A.M.; Weiß, C.; Wehling, M. Consensus Validation of the FORTA (Fit fOR The Aged) List: A Clinical Tool for Increasing the Appropriateness of Pharmacotherapy in the Elderly. Drugs Aging 2014, 31, 131-140. [CrossRef]

46. Wehling, M. Arzneimitteltherapie im alter: $\mathrm{Zu}$ viel und zu wenig, was tun? Ein neues bewertungssystem: Fit for the aged (FORTA). Dtsch. Med. Wochenschr. 2008, 133, 2289-2291. [CrossRef]

47. Winit-Watjana, W.; Sakulrat, P.; Kespichayawattana, J. Criteria for high-risk medication use in Thai older patients. Arch. Gerontol. Geriatr. 2008, 47, 35-51. [CrossRef]

48. Rancourt, C.; Moisan, J.; Baillargeon, L.; Verreault, R.; Laurin, D.; Grégoire, J.-P. Potentially inappropriate prescriptions for older patients in long-term care. BMC Geriatr. 2004, 4, 9. [CrossRef]

49. Poudel, A.; Ballokova, A.; Hubbard, R.; Gray, L.C.; Mitchell, C.A.; Nissen, L.M.; Scott, I. Algorithm of medication review in frail older people: Focus on minimizing the use of high-risk medications. Geriatr. Gerontol. Int. 2016, 16, 1002-1013. [CrossRef]

50. McLeod, P.J.; Huang, A.R.; Tamblyn, R.M.; Gayton, D.C. Defining inappropriate practices in prescribing for elderly people: A national consensus panel. Can. Med. Assoc. J. 1997, 156, 385-391.

51. Laroche, M.-L.; Charmes, J.-P.; Merle, L. Potentially inappropriate medications in the elderly: A French consensus panel list. Eur. J. Clin. Pharmacol. 2007, 63, 725-731. [CrossRef]

52. Basger, B.J.; Chen, T.F.; Moles, R.J. Inappropriate Medication Use and Prescribing Indicators in Elderly Australians Development of a Prescribing Indicators Tool. Drugs Aging 2008, 25, 777-793. [CrossRef]

53. Van der Spek, K.; Gerritsen, D.L.; Smalbrugge, M.; Nelissen-Vrancken, M.H.; Wetzels, R.B.; Smeets, C.H.; Zuidema, S.U.; Koopmans, R.T. A reliable and valid index was developed to measure appropriate psychotropic drug use in dementia. J. Clin. Epidemiol. 2015, 68, 903-912. [CrossRef]

54. Holmes, H.M.; Sachs, G.A.; Shega, J.W.; Hougham, G.; Hayley, D.C.; Dale, W. Integrating Palliative Medicine into the Care of Persons with Advanced Dementia: Identifying Appropriate Medication Use. J. Am. Geriatr. Soc. 2008, 56, 1306-1311. [CrossRef]

55. Kröger, E.; Wilchesky, M.; Marcotte, M.; Voyer, P.; Morin, M.; Champoux, N.; Monette, J.; Aubin, M.; Durand, P.J.; Verreault, R.; et al. Medication Use Among Nursing Home Residents With Severe Dementia: Identifying Categories of Appropriateness and Elements of a Successful Intervention. J. Am. Med. Dir. Assoc. 2015, 16, 629.e1-629.e17. [CrossRef]

56. INFARMED. Deliberação 09/CD/2010. 2010. Available online: https://www.infarmed.pt/docu-428ments/15786/121941 5/delib_09_CD_2010_Uni\%25E3o_Miseric\%25F3rdias\%2520Portuguesas.pdf/4bb6580c-ec1a-4b6a-b2d4-4298cc1dddbb0a0 (accessed on 1 December 2021).

57. Thomson, M.S.; Gruneir, A.; Lee, M.; Baril, J.; Field, T.S.; Gurwitz, J.H.; Rochon, P.A. Nursing Time Devoted to Medication Administration in Long-Term Care: Clinical, Safety, and Resource Implications. J. Am. Geriatr. Soc. 2009, 57, 266-272. [CrossRef]

58. Alves-Conceição, V.; da Silva, D.T.; de Santana, V.L.; dos Santos, E.G.; Santos, L.M.C.; de Lyra, D.P. Evaluation of pharmacotherapy complexity in residents of long-term care facilities: A cross-sectional descriptive study. BMC Pharmacol Toxicol. 2017, 18, 59. [CrossRef]

59. Fagundes, D.F.; Costa, M.T.; Alves, B.B.D.S.; Benício, M.M.S.; Vieira, L.P.; Carneiro, L.S.F.; Nascimento, O.J.M.; Junior, R.S.M. Prevalence of dementia in long-term care institutions: A meta-analysis. J. Bras. Psiquiatr. 2021, 70, 59-67. [CrossRef]

60. Helvik, A.S.; Engedal, K.; Benth, J.Š.; Selbæk, G. Prevalence and Severity of Dementia in Nursing Home Residents. Dement. Geriatr. Cogn. Disord. 2015, 40, 166-177. [CrossRef]

61. Curtin, D.; Gallagher, P.F.; O'Mahony, D. Explicit criteria as clinical tools to minimize inappropriate medication use and its consequences. Ther. Adv. Drug Saf. 2019, 10. [CrossRef] 
62. Chang, C.-B.; Chan, D.-C. Comparison of Published Explicit Criteria for Potentially Inappropriate Medications in Older Adults. Drugs Aging 2010, 27, 947-957. [CrossRef] [PubMed] 